\title{
“UN HONORÍFICO EMPLEO”. APUNTES PARA EL ESTUDIO DE LOS DEFENSORES DE POBRES EN EL RÍO DE LA PLATA (SIGLOS XVIII- XIX) $)^{1}$
}

\section{“AN HONORIFIC JOB”. NOTES FOR THE STUDY OF THE DEFENSORES DE POBRES IN THE RÍO DE LA PLATA (XVIII-XIX CENTURIES)}

\author{
Lucas Rebagliati \\ Universidad de Buenos Aires - UBA - (Buenos Aires, Argentina)
}

Recebimento: 1 jun. 2017

Aceitação: 11 ago. 2017

\begin{abstract}
Como citar este artigo / How to cite this article (informe a data atual de acesso / inform the current date of access):
REBAGLIATI, Lucas. "Un honorífico empleo”. Apuntes para el estudio de los defensores de pobres en el Río de la Plata (siglos XVIII-XIX). Revista da Faculdade de Direito UFPR, Curitiba, PR, Brasil, v. 62, n. 3, p. 157-186, set./dez. 2017. ISSN 2236-7284. Disponível em: <http://revistas.ufpr.br/direito/article/view/52965>. Acesso em: 21 dez. 2017. DOI: http://dx.doi.org/10.5380/rfdufpr.v62i3.52965.
\end{abstract}

\section{RESUMEN}

El presente artículo pretende delinear una serie de observaciones metodológicas e historiográficas de modo de contribuir al abordaje de un agente de la administración de justicia colonial que ha sido poco explorado por la historiografía. Nos referimos a los Defensores de pobres de los cabildos, los cuales actuaron en varias ciudades del Virreinato del Río de la Plata entre fines del siglo XVIII y las primeras décadas del siglo XIX. Nuestra exposición constará de cuatro partes. En la primera de ellas situaremos en contexto la problemática, dando cuenta de la importancia que puede haber llegado a revestir esta figura particular en la época. En segundo término, haremos un recorrido historiográfico, dando cuenta de los aportes realizados por varios estudios, pero a su vez describiendo los motivos que a nuestro entender explican la escasa atención que los historiadores dedicaron al estudio de los Defensores de pobres. En tercer lugar brindaremos un panorama de las variaciones regionales que caracterizaron al oficio en cuestión, basándonos en las actas capitulares éditas de varios ayuntamientos. Por último, haremos un bosquejo de los principales retos metodológicos que afronta quien pretenda abordar dicho objeto de estudio, basándonos primordialmente en los interrogantes y escollos derivados de un estudio de caso.

\section{PALABRAS CLAVE}

Defensores de pobres. Época colonial. Río de la Plata. Justicia.

\footnotetext{
${ }^{1}$ Agradezco los comentarios vertidos a una primera versión de este texto en las XXVI Jornadas de Historia del Derecho Argentino, organizadas por el Instituto de Investigaciones de Historia del Derecho durante mayo de 2016, en la ciudad de San Miguel de Tucumán, Argentina. También soy deudor de los señalamientos y observaciones recibidos en la Duodécima sesión del Seminario Sociedad Indiana (videoconferencia vía Skype), organizada por el Grupo sobre Historia Social de los Mundos Indianos, establecido en el Instituto de Investigaciones Históricas de la UNAM, México, llevada a cabo el 31 de marzo de 2017 [N. do A.].
} 


\begin{abstract}
The present article tries to delineate some methodological and historiographical observations in order to contribute to the approach of an administration agent of colonial justice that has been poorly explored by historiography. We refer to the Defensores de pobres (Defenders of poor) of the city councils, who served in several regions of the Viceroyalty of the Rio de la Plata between the end of the eighteenth century and the first decades of the nineteenth century. Our article will consist of four parts. In the first of them we will situate the theme in context, giving account of the importance that may have had that particular post at the time. Secondly, we will show an historiographic view, reporting the contributions made by several studies, but at the same time describing the reasons which explain the poor attention that historians devoted to the study of the Defensores de pobres. Thirdly, we will give an overview of the regional variations that characterized the post in question, based on the written records of several city councils. Finally, we will outline the main methodological challenges face by those who intend to approach this research topic, mainly based on the questions and obstacles coming from the study of a case.
\end{abstract}

\title{
KEYWORDS
}

Defensores de pobres. Colonial Period. Río de la Plata. Justice.

\section{INTRODUCCIÓN: EL PATROCINIO JURÍDICO A LOS MISERABLES EN EL NUEVO MUNDO}

El descubrimiento y la conquista del Nuevo Mundo plantearon desde el inicio numerosos desafíos a los reyes católicos. A la inmensidad del territorio y la heterogeneidad de las poblaciones nativas se le sumó también la autonomía que exhibieron quienes lideraron el avance en terreno americano y fundaron los primeros asentamientos y ciudades. Una combinación de guerras de conquista, propagación de enfermedades y trabajos forzados pronto dio inicio a una verdadera debacle demográfica entre los indígenas (GARAVAGLIA, 2005; SÁNCHEZ-ALBORNOZ, 1990). Este hecho, estrechamente vinculado al maltrato al que fueron sometidas las poblaciones originarias provocó denuncias por parte de eclesiásticos, siendo los más célebres de ellos Antonio de Montesinos y Bartolomé de las Casas.

El intenso debate relativo a la condición de los indígenas acontecido en la península que culminó con el triunfo de la postura de que los naturales eran libres en el año 1500, claramente no había eliminado la explotación y los abusos, ni morigerado la mortandad resultante. En consecuencia, desde la segunda mitad de esa centuria los indígenas fueron incluidos conceptualmente dentro de la categoría de miserable por parte de eclesiásticos, autoridades y juristas, al mismo tiempo que se fue dictando una profusa legislación protectora sobre ellos (CASTAÑEDA DELGADO, 1971; CEBREIROS ÁLVAREZ, 2004; CUNILL, 2011a; DÍAZ COUSELO, 2001; DUVE, 2004, 2006; GARCÍA GALLO, 1982; LÓPEZ DÍAZ-VALENTIN, 2012; OLIVEROS, 1967).

Esta condición jurídica tenía un amplio desarrollo en la tradición del Ius Commune, y en un 
principio en una disposición del emperador Constantino en el año 334 explícitamente estaba reservada a huérfanos, enfermos, inválidos, viudas y “otras personas miserables”. La indefinición acerca de quiénes eran merecedores de éste último calificativo - esta “cláusula abierta” en palabras de Cuena Boy (2006, p. 160) - fue lo que permitió fácilmente la inclusión de los indígenas dentro de esta concepción, quienes además de ser considerados miserables, eran tenidos por rústicos y menores (CLAVERO, 1994). En el siglo siguiente, tanto en la legislación - Recopilación de leyes de los Reynos de Indias (1680) -, como en las principales obras de doctrina jurídica - Política Indiana de Solórzano Pereira (1647) -, se desarrollaron y afirmaron los privilegios de carácter legal y procesal que detentaban los indígenas en su carácter de personas miserables.

En lo relativo a la justicia, dentro de este engranaje legislativo e institucional se destacaron la instalación de juzgados especiales - Juzgado General de Indios del Virreinato de Nueva España, Juzgado de Indios del Cercado de Lima en el Virreinato del Perú (BORAH, 1970, 1985) - y la creación de la figura del Protector de indios o naturales. Sobre este oficio en particular contamos con una profusa bibliografía (ACEVEDO, 1990; BAEZA MARTÍN, 2010; BAYLE, 1945; BONNETT, 1992; CUENA BOY, 1998a, 1998b, 1998c; CUNILL, 2011b, 2012a, 2012b, 2012c; CUTTER, 1986; DE LA TORRE CURIEL, 2010; LUQUE COLOMBRES, 1990; NOVOA, 2016; RUIGÓMEZ GOMEZ, 1988; SARAVIA SALAZAR, 2011-2012, 2012; SUÑE BLANCO, 2005; ZAPATA DE BARRY, 2007).

Desde 1516 fue un título concedido a los obispos para que velasen por el bienestar de los indígenas, controlando los excesos de conquistadores y encomenderos. En 1560 se les quitó a los religiosos esta prerrogativa y décadas más tarde, las reformas toledanas afianzaron la secularización de la función determinando la creación de un Protector General en Lima y Protectores particulares en ciudades y poblados. Estaba previsto que quienes ocupasen ambos cargos fueran legos. En 1582 por unos breves años se eliminaron estos oficios, encargando la protección de los indígenas a las Reales Audiencias, pero pronto se volvieron a establecer por las quejas suscitadas. Sin embargo, las idas y venidas respecto al amparo de las poblaciones nativas no iban a desaparecer. En el siglo XVII, con el objetivo de institucionalizar y jerarquizar aún más al cargo de Protector de Indios, se determinó que debía ser ejercido por un Fiscal letrado de la Real Audiencia nombrado directamente por el Rey, con la misma jerarquía que los Fiscales civiles y del crimen.

Este sistema también decayó al cabo tres décadas. Y a mediados de la centuria ya se habían vuelto a nombrar Protectores legos que actuaban al margen de las Reales Audiencias. El último cambio significativo experimentado por la Protectoría de naturales ocurrió cuando la función fue reabsorbida por los Fiscales del crimen de las Audiencias, hasta su desaparición formal con la sanción 
de la Constitución de Cádiz en 1812 (CUENA BOY, 1998a; SARAVIA SALAZAR, 2011-2012).

La preocupación de la corona por garantizar que los indígenas contasen con instituciones y funcionarios que resguardasen sus derechos se enmarcaba en un sistema político donde el impartir justicia ocupaba un lugar preponderante (ZORRAQUÍN BECÚ, 1952, 1954). La justicia distaba de ser una rama del gobierno claramente separada de las demás, sino que era una atribución de todas las autoridades que detentaban iurisdictio (AGÜERO, 2006, p. 28-31; VALLEJO, 2009). En razón de ello, el accionar de las justicias legitimaba un orden político en múltiples niveles, dada la imposibilidad de controlar un territorio tan vasto con el solo imperio de la fuerza. El territorio americano era muy extenso e impedía reunir rápidamente un ejército numeroso en un punto determinado (GELMAN, 2000; McFARLANE, 2008).

Con lo cual, si bien la coerción no estaba ausente, los acuerdos y pactos de gobernabilidad requerían un delicado equilibrio entre las aspiraciones de diversos actores sociales. Este consenso se retroalimentaba mediante un sistema jurídico flexible que permitía la inobservancia de algunas normas reales, tomaba en cuenta las costumbres locales, y daba lugar a que distintos sectores sociales peticionaran por sus derechos (MARTIRÉ, 2005; TAU ANZOÁTEGUI, 2001). Esta justicia debía alcanzar incluso a los vasallos más desamparados para el mantenimiento del orden público. Como bien se señalaba en diccionarios de la época el patrocinio de los miserables por parte de las autoridades era fundamental para “...mantener en paz un reino, administrando justicia y deshaciendo agravios..."2.

Pero los pobres y miserables en los dominios hispanoamericanos estaban lejos de reducirse a la población originaria. Los grupos plebeyos hispanoamericanos se componían también de africanos y afrodescendientes - libres y esclavos -, mestizos y “blancos” pobres. Éstos últimos eran individuos que a pesar de cumplir en teoría con el requisito de pureza de sangre, no eran ajenos a las privaciones sociales y económicas de la plebe urbana y rural. A fines del siglo XVIII, el intenso mestizaje y la mercantilización de las relaciones sociales provocaron que las categorías socio-étnicas se volvieran fluidas, porosas y objeto de disputa ${ }^{3}$. El rígido sistema de castas o pigmentocracia implementado por los conquistadores, que buscaba esencialmente clasificar rígidamente a las poblaciones coloniales en españoles, indios y negros dejó de tener una completa efectividad por la aparición de mestizos o mulatos. A ello se le sumó la existencia de la posibilidad para muchos sujetos de "blanquearse”,

\footnotetext{
${ }^{2}$ Diccionario de la Real Academia Española, (RAE), ediciones de 1732, 1780, 1783, 1791, 1803 y 1817, disponible en: www.rae.es.

${ }^{3}$ En respuesta a esta situación, las elites americanas intensificaron las restricciones jurídicas tendientes a marginar a la población de color y a las llamadas castas. Un buen estado de la cuestión que enfatiza la necesidad de problematizar las categorías socioétnicas presentes en las fuentes coloniales lo representa BOIXADÓS y FARBERMAN, 2009.
} 
producto de una migración, el poder económico, el capital relacional, etc. ${ }^{4}$

Estos individuos tenidos por españoles - aunque estrictamente no lo fueran - eran sobre todo numerosos en algunas jurisdicciones de la región rioplatense, donde a diferencia de lo que ocurría en buena parte de los Virreinatos del Perú y Nueva España, la población indígena era proporcionalmente menor. La expresión más clara - aunque extrema - de esta tendencia lo proporciona la ciudad de Buenos Aires, donde un censo de 1778 arrojaba que los españoles - individuos nacidos en la península o en América, tenidos por blancos y con exclusiva descendencia española - eran el 66,8 \% de la población, mientras que los negros y mulatos eran el 28,4 \% y los indios y mestizos solo el 4,8 \%. En la campaña circundante, nos encontramos con el mismo patrón. Otras regiones donde la población considerada blanca era mayoría eran Córdoba y Paraguay. En otras jurisdicciones del norte, como Santiago del Estero, Jujuy o Tucumán, la población indígena era más numerosa (FRADKIN, 2009).

¿Quién patrocinaba a estos pobres no indígenas ante los tribunales? Como hemos visto la tradición del Ius Commune originariamente reservaba un trato especial a diversos grupos de desamparados, y de ello se hizo eco la Recopilación de leyes de los Reynos de Indias, la cual contenía normas referentes a pobres, ancianos, niños, huérfanos, presos y enfermos ${ }^{5}$. Los pleitos de pobres tenían fijado un día especial - los sábados - debían concluirse con celeridad, y las personas necesitadas quedaban exceptuadas del pago de ciertos aranceles. Dentro de estas medidas, una de las que se destacaba era la provisión de abogados gratuitos a los litigantes menesterosos. En la península, eran los mismos concejos locales quienes costeaban a estos profesionales, aunque también los abogados de pobres formaban parte de las instituciones de justicia reales. ¿Existían en las ciudades del Nuevo Mundo abogados de pobres costeados por las autoridades? En un interesante estudio

\footnotetext{
${ }^{4}$ La posibilidad de blanqueamiento social de todas formas no era universal, ni se daba con la misma frecuencia en todas partes. En la jurisdicción de Buenos Aires, el fenómeno acontecía en la ciudad con los migrantes de regiones de alto componente indígena (DÍAZ, 1998), aunque con más frecuencia en la campaña donde existían estructuras sociales más laxas (FARBERMAN; RATTO, 2009). Eran los pardos de piel clara y los mestizos quienes tenían más chances blanquearse socialmente. En otras regiones - como Catamarca - el proceso de blanqueamiento de la población de color databa de fines de la época colonial, producto de un intenso mestizaje y una alta proporción de afroamericanos libres (GUZMÁN, 2010).

${ }^{5}$ Recopilación de leyes de los Reinos de las Indias mandadas a imprimir y publicar por la majestad católica del Rey Don Carlos II Nuestro Señor, Tomos I y II. Madrid, Boix, 1841. Normas sobre los indígenas: Tomo I, Libro II, Título XVIII, Leyes XXXIV y XXXVII. Tomo I, Libro II, Título XXII, Ley XXVIII. Recopilación de leyes..., Tomo I, Libro II, Título XXIX, Ley I. Tomo I, Libro II, Título XXIX, Leyes IV y XIV. Tomo I, Libro II, Título XXXI, Leyes I, VIII, X, XI, XII, XIII y XIV. Tomo II, Libro VI, Títulos I-XIX. Disposiciones sobre enfermos: Tomo I, Libro I, Títulos IV, Ley I. Tomo I, Libro I, Títulos IV, Ley III. Tomo I, Libro I, Títulos IV, Leyes X, XIV y XVIII. Leyes referentes a los presos: Tomo II, Libro VII, Título VI, Leyes II, III, VIII, IX, X. Tomo II, Libro VII, Título VI, Leyes XIII, XVI, XVII, XVIII, XXI. Tomo II, Libro VII, Título VII. Huérfanos y niños son contemplados en Tomo I, Libro V, Título III, Leyes XVII, XVIII, XIX. Tomo II, Libro VII, Título IV, Ley IV. Los beneficios de ancianos y pobres en: Tomo II, Libro VII, Título V, Ley I. Tomo I, Libro II, Título XXII, Leyes XXII y XLVIII. Tomo I, Libro II, Título XXIV, Leyes XXVI y XXVII. Tomo II, Libro V, Título XIII, Ley IV.
} 
artículo destinado a describir el marco normativo de las garantías procesales que tenían los litigantes pobres en los dominios americanos se afirmaba que:

\begin{abstract}
...de aquellos dos ámbitos castellanos en los que era dado detectar la presencia de abogados de pobres: corporaciones locales y altos órganos de administración de justicia, puede decirse que es en este último donde se percibe una mayor vigencia de la institución desde época temprana. La explicación de este hecho debe buscarse en la escasez de abogados en Indias hasta el siglo XVIII y su consiguiente escasa presencia en tribunales de justicia de ámbito local, donde se procuraba una administración de justicia rápida y poco formalista (BERMÚDEZ AZNAR, 1980, p. 1.047).
\end{abstract}

La extensión del Virreinato del Perú - que abarcaba todos los dominios que la corona tenía en América del sur - seguramente dificultaba el acceso de los miserables a los procuradores de pobres de las Reales Audiencias. Sobre todo en los territorios meridionales de este enorme Virreinato Gobernaciones del Tucumán, del Río de la Plata y del Paraguay - los cuales estaban bajo jurisdicción de la lejana real Audiencia de Charcas. Quizá por esta razón los gobernadores de las provincias del Río de la Plata en las primeras dos décadas del siglo XVIII tenían la costumbre de nombrar un “Protector general de naturales y demás personas pobres miserables negros y mulatos” para que los defendieran “en todas sus causas civiles y criminales”, costeado por la administración real ${ }^{6}$.

De todas formas, la existencia de este oficio era a las claras insuficiente para garantizar el acceso a la justicia a los grupos plebeyos y desamparados como indígenas, afrodescendientes o simplemente pobres. Este hecho, combinado con la ausencia de abogados en muchas ciudades, sin embargo no necesariamente derivó en una administración de justicia al margen de las formalidades procesales como ha sido señalado, sino que abrió un margen para que los ayuntamientos locales ensayaran distintas soluciones al problema presentado.

Las medidas adoptadas exhibieron una heterogeneidad significativa, lo cual no hace más que evidenciar una vez más la importancia jugada por el derecho local en los dominios hispanoamericanos (TAU ANZOÁTEGUI; AGÜERO, 2013). Este tema será desarrollado en el tercer apartado del presente trabajo. Sólo adelantaremos que los cabildos confiaron a ciertas personas de renombre los títulos de Protectores de naturales, Defensores de Menores y Defensores de pobres. En algunos casos estas figuras eran externas al ayuntamiento, en otros solo representaban funciones asignadas a algún regidor, y en algunos casos constituían un oficio capitular específico. También al realizar una observación empírica caso por caso, puede verse como algunas de estas funciones estaban fusionadas en una misma persona, o cómo a lo largo del tiempo un mismo ayuntamiento fue modificando su

\footnotetext{
${ }^{6}$ Acuerdos del extinguido Cabildo de Buenos Aires (AECBA). Buenos Aires, Kraft, 1925-1933. Tomo I, Serie II, p. 161163. Tomo II, Serie II, p. 335-336. Tomo III, Serie II, p. 54-55.
} 
política en torno al tema.

Precisamente este trabajo pretende - a raíz de los interrogantes surgidos producto de una investigación doctoral concluida y defendida recientemente (REBAGLIATI, 2016b) - realizar algunas observaciones metodológicas e historiográficas en torno al estudio de los Defensores de pobres que actuaron en varias ciudades del Virreinato del Río de la Plata a fines de la época colonial. Ya hemos mencionado que la historiografía ha prestado considerable atención a los Protectores de indios o naturales. En cambio sobre otros agentes de justicia encargados de representar a los pobres y miserables ante los tribunales - como los Procuradores de pobres de las Reales Audiencias o los Defensores de pobres y de menores de los cabildos - sabemos mucho menos ${ }^{7}$.

A continuación haremos un breve repaso por la historiografía que ha tratado este objeto de estudio o temas cercanos. En segundo lugar, analizaremos la información disponible sobre el oficio de Defensor de pobres que se desprende de las actas capitulares éditas de varias ciudades del virreinato del Río de la Plata. En tercer lugar, delinearemos una serie de prevenciones metodológicas surgidas al calor de un estudio de un caso: los Defensores de pobres del cabildo de Buenos Aires entre 1776 y 1821.

\section{LA HISTORIOGRAFÍA SOBRE EL TEMA. LAS RAZONES DE UNA AUSENCIA}

En general puede señalarse que la figura del Defensor de pobres ha concitado escasa atención por parte de la historiografía. Destacados estudios sobre la justicia colonial aparecidos en las primeras tres décadas del siglo XX no trataron el tema (LEVENE, 1924; MALAGON BARCELÓ, 1936; RUIZ GUIÑAZÚ, 1916) ${ }^{8}$. La década de 1940 sería prolífica en lo referente a la aparición de obras dedicadas a estudiar el llamado Derecho indiano, especialmente en lo referente al "régimen municipal” o al derecho procesal penal, pero esto no redundó automáticamente en mayores precisiones sobre nuestro objeto de estudio (ÁVILA MARTEL, 1941, 1946; LEVENE, 1945, 1952; OTS CAPDEQUÍ, 1943). Hubo excepciones a este panorama, ya que dos estudios constataron la existencia del cargo de

\footnotetext{
${ }^{7}$ Esta tendencia reconoce excepciones. Algunos estudios si se han enfocado en estos actores que actúan como mediadores entre las justicias y los sectores subalternos (AZEVEDO, 2007; GAYOL, 2002; GONZÁLEZ UNDURRAGA, 2012; PUGLIESE, 1996, 2000; REBAGLIATI, 2010, 2016; ZAPATA DE BARRY, 2013).

${ }^{8}$ Por ejemplo, Enrique Ruiz Guiñazú, en su reconocido La magistratura indiana (1916) dedicó sendas páginas a las Reales Audiencias, los Alcaldes ordinarios del Cabildo, los Corregidores, el Protector de Naturales e incluso los abogados. Sin embargo, los Defensores de pobres no fueron mencionados en la obra. Una excepción a esta tendencia la constituyó Tomás Jofré (1913), quien reduciendo la escala de observación a la ciudad de Buenos Aires, advirtió la presencia de un defensor de pobres designado por el cabildo. El apéndice documental que acompañaba a su estudio introductorio consistente en la transcripción de unas veinte causas judiciales correspondientes al período - también permitió ver al Defensor de pobres en acción representando a esclavos y gente del común en procesos criminales. Lamentablemente, estas breves menciones al Defensor de pobres fueron olvidadas rápidamente.
} 
Defensor de pobres, pero solo lo mencionaron al pasar, sin abundar en las atribuciones del mismo (IBAÑEZ FROCHAM, 1938; MÉNDEZ CALZADA, 1944) ${ }^{9}$. Algunos de los estudios de síntesis más representativos sobre los ayuntamientos en América tampoco hicieron mención a los Defensores de pobres (BAYLE, 1952; HARING, 1966) ${ }^{10}$.

En décadas subsiguientes por debajo de estas grandes narrativas diversos estudios constataron la presencia de los Defensores de pobres, aunque no los tuvieran en el foco de su interés. Básicamente estas obras tuvieron tres campos de estudio: El funcionamiento de los cabildos americanos (DEL VALLE, 2014; SÁENZ VALIENTE, 1950; ZORRAQUÍN BECÚ, 1956), la administración de justicia y la visita de cárcel (ASPELL DE YANZI FERREIRA, 1997; LEVAGGI, 1976, 2002; MARILUZ URQUIJO 1961; MARTIRÉ, 1987; ZORRAQUÍN BECÚ 1952, 1956) y la situación jurídica de la población afroamericana (LEVAGGI, 1973; PEÑA DE MACARLUPU, 1993; PETIT MUÑOZ, 1947; PLA, 1972).

Todos estos estudios, encuadrados la gran mayoría en la Historia del derecho, fueron realizando aportes sustanciales y delimitando líneas de investigación. Sin embargo, el lugar reservado a los Defensores de pobres en los manuales de síntesis sobre el Derecho indiano rioplatense siguió siendo menor o directamente nulo (GARCÍA BELSUNCE, 1977; LEVAGGI, 1978, 2005; LEVENE, 1961; TAU ANZOÁTEGUI; MARTIRÉ, 1981; ZORRAQUÍN BECÚ, 1978) ${ }^{11}$. Algo llamativo es que los Defensores de pobres tampoco fueron mencionados en algunos trabajos concretos que enfatizaron el resguardo de derechos personales y garantías procesales durante el Antiguo Régimen (MARILUZ URQUIJO, 1961; MARTIRÉ, 1980).

En paralelo a estas aproximaciones, desde la historia social y la nueva historia política también los defensores de pobres empezaron a aparecer en forma marginal y secundaria, en investigaciones que tenían otros intereses (BARRENECHE, 1993, 1995, 2001; BERNAND, 2001; CANDIOTI, 2010a, 2010b; CASAGRANDE, 2012; DI MEGLIO, 2006; FERNÁNDEZ, 2007; FRADKIN, 2009; JOHNSON, 2007; MALLO, 1991; PERRI, 2009; SOCOLOW, 1991). La mayoría de estos estudios, hacían referencia a los Defensores de pobres porteños. Pero en las últimas décadas,

\footnotetext{
${ }^{9}$ Mientras el primero de estos autores confirmó su existencia en el período colonial y luego los volvió a mencionar al tratar las Ordenanzas capitulares de 1814, el segundo solo hizo una mención al pasar en su capítulo sobre las garantías procesales en el Antiguo Régimen.

${ }^{10}$ Ello era entendible en algunas obras que por tener un carácter tan general, inevitablemente debían renunciar a realizar una descripción minuciosa del ayuntamiento, como el capítulo que Clarence Haring dedicó a los cabildos en su obra de síntesis dedicada al imperio hispánico. Mucho más difícil de explicar, es la completa omisión de los Defensores de pobres en la voluminosa obra de Constantino Bayle. Allí el autor enumeró muchos de los cargos desempeñados por los regidores como el de Alguacil Mayor, Fiel Ejecutor, Procurador. En otro capítulo también hizo comentarios sobre ciertos oficios extracapitulares como los pregoneros, el protector de naturales, el mayordomo, el capellán, el verdugo y hasta el portero.

${ }^{11}$ En esta última obra - cuya edición original data de 1966 - hay una mención sobre los Defensores de pobres y menores.
} 
los Defensores de pobres del interior del virreinato - como Tucumán, Córdoba o Paraguay - también han sido mencionados en estudios enfocados en la población afrodescendiente, los pobres y la justicia (AGÜERO, 2008; PAROLO, 2008; RUFER, 2001; TELESCA, 2010; TÍO VALLEJO, 2001; ZAMORA, 2011).

Recién a mediados de la década de 1990 apareció un estudio enfocado exclusivamente en la temática. En un artículo pionero aparecían delineadas a grandes rasgos las principales funciones que tenían a su cargo estos regidores (PUGLIESE, 1996). En un trabajo posterior, la misma autora brindó un listado de los Defensores de pobres que actuaron en el período virreinal, describiendo las cargas inherentes al cargo, y las relaciones entabladas entre ellos y los abogados que habitaban la ciudad a fines del período colonial (PUGLIESE, 2000). En años recientes, otra autora - desde una perspectiva jurídica - también tendría a los Defensores de pobres del Virreinato de Río de la Plata en el centro del análisis, aunque enfocándose prioritariamente en una sola de sus funciones (ZAPATA DE BARRY, 2007, 2013). Ambas autoras orientaron su atención mayoritariamente en los Defensores de pobres de la ciudad de Buenos Aires.

En resumen, las aproximaciones a los Defensores de pobres que actuaron en la época tardocolonial en el Río de la Plata, o bien fueron sesgadas producto de que esta temática no constituía el objeto primordial de atención, o brindaron un panorama general sin ahondar profundamente en las prácticas de estos actores. A su vez, es claro que los Defensores de pobres de Buenos Aires fueron más estudiados que sus colegas del interior. Estos tres factores explican en parte que las apreciaciones sobre los Defensores de pobres sean tan disímiles. Algunas de estas conclusiones también son contrapuestas entre sí producto de diferentes enfoques o perspectivas.

Sobre los Defensores de pobres se ha afirmado que eran: abogados ilustrados que propagaron ideas de avanzada para su época, notables cuyo único interés era defender la propiedad de los estamentos superiores, celosos y comprometidos defensores de encarcelados y esclavos, desganados “funcionarios” que no se preocupaban por la suerte de sus defendidos, sujetos que abrumados por las tareas inherentes al cargo hicieron cuanto estuvo a su alcance, defensores de abusadores que retroalimentaban la cultura machista de la época, agentes de justicia que desplegaban variadas estrategias en pos de paliar las desventuras de quienes ocupaban el último peldaño de la sociedad, regidores que construían una concepción paternal de la autoridad política en sus niveles inferiores, personas de la elite cuya única función era resguardar algunos derechos de las clases subalternas para legitimar un sistema de dominación colonial de naturaleza patriarcal y estamental, etc.

Acerca de la validez de conclusiones tan disímiles haremos algunos señalamientos en el último apartado. Por lo pronto cabe interrogarse acerca de la razón por la cual los Defensores de 
pobres no concitaron la atención de los estudiosos del derecho durante buena parte del siglo XX. Esta pregunta cobra mayor sentido si consideramos que desde muy temprano los estudiosos de la historia del derecho no solo advirtieron la centralidad de la administración de justicia en la organización política del imperio español en América, sino que en su debate contra la “leyenda negra”, buscaron matizar considerablemente la imagen de arbitrariedad, despotismo, ilegalidad y violencia que se tenía del dominio colonial español en América. ¿Qué mejor idea que estudiar a quienes facilitaban el acceso a la justicia a los sectores más desfavorecidos de la sociedad?

Si bien nuestro interrogante no conoce respuestas simplistas, aventuraremos alguna hipótesis al respecto. El silencio o los escasos comentarios sobre los Defensores de pobres en las obras fundadoras de la Historia del derecho puede explicarse en parte por las escasas menciones existentes en la legislación de época sobre este cargo. La normativa contenida en la Recopilación de las leyes de los reynos de Indias, - particularmente el título nueve titulado "De los Cabildos y Concejos” y el título diez "De los oficios concejiles" - guardaba silencio sobre los Defensores de pobres. Las ordenanzas del Cabildo de Buenos Aires de 1695 tampoco hicieron referencia al cargo de Defensor de pobres, aunque si señalaban la necesidad de que un regidor asistiera a las visitas de cárcel, y velara por la prontitud de los procesos judiciales y la soltura de los encarcelados ${ }^{12}$.

De hecho, las normas que regulaban las obligaciones de los Defensores de pobres porteños parecerían haber consistido en ciertas costumbres de las que dan cuenta representaciones que el cabildo realizaba ante las autoridades reales y algunas disposiciones de los gobernadores y de la Real Audiencia. Por ejemplo, un bando del gobernador Don Joseph de Andonaegui en 1755 habilitó que quienes tramitaran la información de pobreza pudieran ser representados por el Defensor de pobres ${ }^{13}$. Pero luego un auto de la Real Audiencia de 1786 y ratificado en 1804 redujo las personas susceptibles de ser atendidas por el Defensor de pobres a los desamparados que se hallaban en prisión.

La necesidad de repetir y ratificar una misma norma casi veinte años después es indicativa de su incumplimiento en la práctica. De hecho los Defensores de pobres de la ciudad de Buenos Aires en el período virreinal cumplieron en lo esencial cuatro funciones. Asistían legalmente a los pobres solemnes - individuos que habían obtenido una certificación de pobreza por parte de la Real Audiencia en pos de pleitear sin costos - en sus litigios civiles. Representaban durante los juicios a los procesados criminalmente que no tenían recursos para ejercer su propia defensa. Tenían a cargo

\footnotetext{
${ }^{12}$ Estatutos y Ordenanzas de la ciudad de la Santísima Trinidad puerto de Santa María de Buenos Aires. Buenos Aires, Edición facsimilar ofrecida por la Institución Cultural Española en recuerdo de la restauración de la sala capitular del Cabildo, 1939.

${ }^{13}$ A.G.N., Sala IX 8-10-2, Folios 116-117, Bandos de los virreyes y gobernadores del Río de la Plata (1741-1809) (en adelante Bandos de Buen Gobierno), Don Joseph de Andonaegui, Buenos Aires, 12 de junio de 1755.
} 
el patrocinio de esclavos en ciertos litigios tanto civiles como criminales - en este último caso el defensor intervenía cuando el amo se había desentendido del patrocinio de su esclavo. Y por último participaban de la visita de la cárcel, velando por las condiciones de detención de los presos y peticionando en favor de los mismos ante las autoridades.

Por lo pronto, el primer cuerpo normativo que definió explícitamente las funciones del Defensor de pobres porteño fueron las ordenanzas capitulares de 1814. Sin embargo, las obligaciones prescriptas en dichas normas también sufrieron modificaciones posteriores sobre todo por las quejas de los defensores acerca de lo oneroso de su tarea. La mencionada indeterminación normativa acerca del oficio del Defensor de pobres puede explicar en gran parte el hecho de que dicho cargo estuvo lejos de representar una figura claramente diferenciada de otros oficios en todos los cabildos rioplatenses. De hecho otro de los factores que seguramente ha influido en la poca atención que la historiografía le prestó a le temática debe ser la tardía aparición del oficio en la mayoría de las ciudades rioplatenses - recién a finales del siglo XVIII -, con la excepción de Buenos Aires donde el oficio se creó formalmente en 1722. El proceso de aparición del oficio revistió características particulares de acuerdo a la ciudad en la que enfoquemos nuestra atención. Es hora que exploremos - al menos superficialmente - estas variaciones regionales.

\section{LAS DEFENSORÍAS DE POBRES DE LOS AYUNTAMIENTOS RIOPLATENSES: UN CUADRO HETEROGÉNEO}

Los cabildos o ayuntamientos del Virreinato del Río de la Plata - al igual que en el resto de Hispanoamérica - actuaban como tribunales inferiores, administrando la justicia civil y penal en primera instancia. Eran los regidores alcaldes de primer y segundo voto quienes oficiaban de jueces. Las sentencias dictadas por estos alcaldes podían ser apeladas ante los mismos cabildos, los tenientes letrados de cada intendencia, la Real Audiencia - instalada en Buenos Aires desde 1785 - y el Virrey. Sin embargo, no todos los pleitos eran resueltos por los alcaldes, ya que existían tribunales especiales. Entre estos se contaban el tribunal militar, el eclesiástico y el mercantil.

En Buenos Aires existía un Defensor de menores desde 1642, quien era uno de los regidores. Como ya mencionamos, el cargo de Defensor de pobres también fue asignado a un regidor y su origen se remonta a 1722 (PUGLIESE, 1996). Por un breve lapso - de 1760 a 1764 -, dicha función estuvo fusionada con la de Defensor de Menores. Por otro lado, los Defensores de pobres porteños no defendían a los indígenas - tarea a cargo del fiscal Protector de Naturales de la Audiencia desde 1784 - y solo en algunos casos representaban a los esclavos. 
¿Qué sucedía en otras ciudades del virreinato para la misma época? En Córdoba el cargo de Defensor de menores existía en el siglo XVII pero recaía en personas ajenas al Cabildo. Este funcionario estaba encargado de defender también a los indígenas. La figura de Defensor de pobres apareció en el siglo XVIII pero unida a la de Defensor de menores y recién a finales de esta centuria los cargos se desdoblaron y recayeron en distintos regidores capitulares (AGÜERO, 2008, p. 304305).

En Montevideo a mediados del siglo XVIII la función de Defensor y Protector de indios era ejercida por el Alférez real. En 1756 también se creó un cargo permanente de "Defensor de pobres menores y miserables pobres encarcelados”. Quien ocupaba dicho cargo era externo al ayuntamiento porque no tenía voz ni voto pero dependía de la institución capitular. A partir de 1760 desapareció el funcionario especial y quien quedó encargado de la Defensoría de pobres y menores fue el Alférez real. En años subsiguientes el cargo fue alternado entre el Depositario General y el Fiel Ejecutor y excepcionalmente el Alguacil Mayor. En 1804 finalmente los oficios de Defensor de pobres y menores se desdoblaron (PETIT MUÑOZ, 1947, p. 512-526).

El ayuntamiento de la ciudad de San Juan de la Frontera durante buena parte de la segunda mitad del siglo XVIII solamente contó con los Alcaldes ordinarios de $1^{\circ}$ y $2^{\circ}$ voto, otros dos Alcaldes de hermandad y un Procurador general de la ciudad. En 1776 además de los cargos mencionados se eligieron otros oficios como el de Fiel ejecutor, Alguacil mayor, Depositario general y Regidor alcalde provincial. El cargo de Defensor de menores recién apareció en 1789, y el Defensor de pobres en 1811, recayendo ambos oficios en personas distintas. El cargo de Defensor de pobres fue cubierto por distintos regidores en forma anual hasta el año $1822^{14}$.

Por otra parte, el Cabildo de Mendoza durante buena parte del siglo XVIII estuvo compuesto por los Alcaldes ordinarios de primer y segundo voto, un Alguacil mayor, un Alcalde provincial y un Procurador general. Además se nombraban otros oficios extracapitulares como los Alcaldes de la santa hermandad, los Alcaldes de barrio y los Alcaldes de agua. El cargo de Defensor de Menores fue consignado explícitamente solo en cuatro años 1742, 1774, 1775 y 1776 (SANJURJO DE DRIOLLET, 1995, 1997). En 1810, el ayuntamiento designaría por primera vez a un "Defensor de menores y pobres” y a partir de 1815, cuando la cantidad de regidores se amplió de ocho a doce ambas funciones se desdoblaron.

Mendoza contó así con un "Regidor Defensor de pobres” de 1815 a 1823, año en que se

\footnotetext{
${ }^{14}$ Actas capitulares de la ciudad de San Juan de la Frontera (1562-1822). Buenos Aires, Academia Nacional de la Historia, 2009.
} 
abolió el Cabildo. Unas ordenanzas de 1821 establecían que era función de este defensor visitar distintos establecimientos como la cárcel, el presidio y otros lugares “de corrección”. A partir de esta fecha, las funciones que antes desempeñaba el regidor mencionado pasaron a ser desempeñadas por un Defensor de pobres, menores y esclavos, dependiente del incipiente estado provincial y rentado con 400 pesos anuales (ACEVEDO, 1963).

No solo algunas ciudades contaban con un Defensor de pobres, sino también algunos poblados que sin llegar a ser ciudades tenían el estatus de villas. La villa de Luján por ejemplo, tenía cabildo propio desde el año 1756, y en las últimas décadas de la centuria contó con un "Regidor Defensor de Menores” y un "Regidor Defensor general de pobres”. Este último oficio era elegido en las elecciones capitulares, siempre era ocupado por distintos sujetos, y tenía voz y voto en las sesiones del ayuntamiento ${ }^{15}$. Similar caso fue el de la Villa de la Concepción de Río Cuarto, jurisdicción de Córdoba, cuyo cabildo tuvo una existencia más breve aún que la de Luján, de 1795 a 1812. Allí también los oficios de Defensor de Menores y Defensor de pobres no sólo existían, sino que además recaían por separado en dos regidores del cuerpo capitular ${ }^{16}$.

En otras ciudades el oficio de Defensor de pobres nunca se separaría del de Defensor de Menores. Santa Fe de la Vera Cruz contaba con un Defensor de menores del ayuntamiento y un Protector de naturales desde el siglo XVII. Las actas capitulares en 1716 hacen una temprana mención al "Defensor de pobres y menores”. Pero la defensoría conjunta de menores y pobres fue nombrada con regularidad recién desde 1760, recayendo en el Procurador general. En 1773 la función pasó a ser ejercida por un regidor con voz y voto. Pero en 1781 el oficio en cuestión volvió a recaer sobre las espaldas del Procurador general “porque los regidores no podían desempeñarlo”. Lo cierto es que allí no terminaron las idas y venidas. Luego de numerosas súplicas del Procurador general para que lo eximan de la función, en 1801 la defensoría de pobres y menores volvió a ser desempeñada por un regidor elegido anualmente. El cargo de Defensor de pobres se mantuvo unido al de Defensor de Menores por lo menos hasta $1821^{17}$.

Los regidores de Santiago del Estero en la segunda mitad del siglo XVIII nombraban a un Defensor de menores y ocasionalmente a un Protector de indios o naturales. En 1793 por primera vez se dictaminó en un acuerdo capitular que trataba sobre las elecciones del ayuntamiento de ese año

\footnotetext{
${ }^{15}$ Acuerdos del extinguido Cabildo de la Villa de Luján: años 1771 a 1790. Luján, Museo colonial e histórico de la provincia de Buenos Aires, 1930.

${ }^{16}$ Actas capitulares de la Villa de Concepción del Río Cuarto. Años: 1798 a 1812. Buenos Aires, Academia Nacional de la Historia, 1947.

${ }^{17}$ Actas del Cabildo de Santa Fe de la Vera Cruz. Período XVI al XIX. Archivo General de la Provincia de Santa Fe. Disponibles en: <https://goo.gl/ZdWJXd>. Hemos chequeado solo las actas del período 1573-1821.
} 
que la elección de Defensor de menores recaía en Don Pedro Isnardi “que assimismo se declara lo será de pobres”. A partir de allí la Defensoría de menores y de pobres fue encargada a un regidor hasta 1813. De 1814 en adelante se volvió a nombrar en las elecciones capitulares a un "Defensor de menores" a secas ${ }^{18}$.

En San Miguel de Tucumán a fines del período colonial existía el cargo de Defensor de pobres y menores, quien también cumplía las funciones de Protector de naturales asistiendo a los indígenas. Sin embargo, el cargo fue ocupado por un regidor recién a partir de 1799, siendo su nombramiento facultad del Cabildo y con una periodicidad anual (TÍO VALLEJO, 2001, p. 70; ZAMORA, 2011, p. 115-116, 122-124, 130-131). En la ciudad de Catamarca, durante las primeras décadas del siglo XIX, el ayuntamiento nombraba en las elecciones realizadas a inicio de cada año a un “Defensor general de menores y pobres"19.

En otras ciudades no tenemos constancia de que haya existido un Defensor de pobres o de pobres y menores durante el siglo XVIII ${ }^{20}$. El ayuntamiento de San Luis de Loyola durante muchos años solo contaba con dos alcaldes ordinarios y dos alcaldes de hermandad. A partir de 1779 se nombró también a un Síndico procurador general. En 1797 además se nombraron por primera vez Alcaldes de barrio ${ }^{21}$. El cabildo de Itatí - uno de los pocos ayuntamientos de indios de los cuales se conservan las actas - nombraba a fines del siglo XVIII anualmente a dos alcaldes ordinarios, un alcalde provincial, tres regidores llanos, un procurador del pueblo y otro de las estancias, un Alférez real, un Alguacil mayor y por último un Secretario mayor ${ }^{22}$.

Como podemos ver, la experiencia porteña es en algún modo particular, por lo menos en lo que respecta al momento histórico en el que aparece el oficio, ya que de las ciudades que hemos relevado representa el precedente más temprano al respecto. Salvando las particularidades de cada caso concreto - que ya fueran descriptas - en las otras ciudades y villas donde la función se desvinculó de la Defensoría de Menores, esto recién ocurrió a fines del siglo XVIII y principios del XIX. Pero a

\footnotetext{
${ }^{18}$ Actas capitulares de Santiago del Estero. Buenos Aires, Kraft, 1942-1948. Tomos II (1748-1766), III (1767-1777), IV (1778-1791), V (1792-1803) y VI (1806-1833).

${ }^{19}$ Actas capitulares de Catamarca, $1^{\circ}$ de enero de 1815 a 24 de diciembre de 1818, v. II. Buenos Aires, Talleres gráficos de la penitenciaría Nacional, 1935.

${ }^{20}$ La ausencia del oficio de Defensor de pobres en las actas capitulares no necesariamente implica que los pobres $y$ miserables carecieran de sujetos que los representaran en el ámbito de la justicia. Por ejemplo, el análisis de expedientes criminales correspondientes a Buenos Aires deja entrever que esta función podía ser cumplida en ocasiones por un patrón, un pariente, un amigo o conocido o un vecino destacado si así lo autorizaban los alcaldes ordinarios que actuaban como jueces. Incluso es posible que otros regidores como los Defensores de menores cumplieran esta función allí donde el oficio de Defensor de pobres no existía.

${ }^{21}$ Actas capitulares de San Luis, Tomo II, Años 1751 a 1797. Buenos Aires, Academia Nacional de la Historia, 1983.

${ }^{22}$ Actas del cabildo de Itatí (Desde el 7 de febrero de 1793 hasta el 24 de diciembre de 1798). Corrientes, Instituto de Investigaciones Geohistóricas, 1980.
} 
su vez también vimos que en algunas ciudades este proceso no se consumó nunca y que en otras la denominación "Defensor de pobres” ni siquiera apareció fusionada a la de "Defensor de Menores" en las elecciones capitulares celebradas por los ayuntamientos.

Al mismo tiempo, las diferencias que se observan en torno a la aparición del oficio en las ciudades analizadas están lejos de ser meramente cronológicas. Quien era denominado Defensor de pobres podía ser interno o externo al ayuntamiento, en algunos casos defendía a los indígenas y en otros no, o podía ser solo una función que rotaba entre distintos regidores y no un oficio específico en cuestión.

\section{A MODO DE CONCLUSIÓN: SOBRE RETOS METODOLÓGICOS, ENFOQUES Y LÍNEAS DE INVESTIGACIÓN}

Nos gustaría cerrar este trabajo exponiendo una serie de reflexiones sobre los desafíos teóricos y metodológicos que creemos conveniente afrontar a la hora de estudiar las prácticas de estos peculiares agentes de justicia. Hemos visto que las conclusiones a las que arribaron la mayoría de estudios que hicieron observaciones sobre los Defensores de pobres son muy disímiles y en algunos casos contrapuestas. Ello no debería sorprendernos. Afirmaciones que en principio parecerían incompatibles, en realidad pueden obedecer a perspectivas complementarias. Si tenemos en cuenta que en la mayoría de los casos se trataba de un oficio capitular, ello implicaba que el cargo era anual y rotativo. Entonces muchas personas desempeñaban esta función, y es esperable que el desempeño en el cargo de cada una de ellas sea variable. En nuestra propia investigación analizamos una muestra de cuarenta y cinco Defensores de pobres y hemos detectado una heterogeneidad significativa.

Pero esta diversidad también es posible de ser advertida al analizar las prácticas de un solo defensor. Pensemos que alguno de estos regidores podría haber mostrado una excelente disposición para mejorar la suerte de los presos pero haber representado a desgano a los esclavos. Incluso dentro de una misma función pueden haber existido diferencias importantes, ya que los Defensores de pobres pueden haber exhibido una constancia admirable en la defensa de reos que estaban condenados a muerte, pero no haber mostrado el mismo empeño en casos de aprehensiones por faltas menores.

¿Impide esta riqueza empírica arribar a cualquier tipo de conclusión o explicación de conjunto? Por supuesto que no. Sólo queremos plantear que el interrogante sobre el desempeño de los Defensores de pobres dista de tener una respuesta unívoca y sencilla. Las conclusiones deben evitar borrar la complejidad del problema y los matices significativos deben encontrar su lugar en la explicación. Cualquier respuesta unívoca o afirmación categórica puede pecar de simplista o 
reduccionista. Si uno analizara el desempeño de medio centenar de Defensores oficiales - del Ministerio Público - en la actualidad también encontraría un variopinto panorama.

Las fuentes arrojan la impresión que algunos Defensores de pobres porteños eran muy destacados en su labor mientras que otros parecían exhibir un desempeño deficiente. Esta apreciación era compartida por los actores de la época, los asistidos por estos defensores. Mientras algunos esclavos solicitaban que los asistiera el Defensor de pobres, otros pedían que por favor el regidor en cuestión dejara de representarlos así ellos podían asumir su propia defensa. Otros esclavos iban más lejos aún y denunciaban complicidad o cercanía de intereses entre los defensores y sus amos. Una solución posible al enfrentarse con tal complejidad, es tratar de abarcar todo el rango de lo posible, dando cuenta del defensor más indolente hasta el más comprometido. Y analizar en qué medida el accionar de estos agentes de justicia mejoraba o aliviaba algunos de los pesares de los pobres, los presos y los esclavos.

Sin embargo también hay que tener en cuenta que a veces una mejora en las condiciones de estos grupos sociales podía no depender exclusivamente de los Defensores de pobres. Por ejemplo, los Defensores de pobres de Buenos Aires realizaron muchas gestiones en alivio de los presos pero al no existir recursos para ampliar la cárcel y solucionar el hacinamiento que sufrían los reclusos, esos esfuerzos en gran medida fueron en vano (REBAGLIATI, 2012). O en los litigios que involucraban a procesados pobres y esclavos un excelente patrocinio legal no era garantía de una sentencia o un fallo favorable. Sobre todo porque otros elementos entraban en juego, tales como la influencia y el poder de la otra parte, la prueba disponible en el proceso, el parecer del juez interviniente, etc. (REBAGLIATI, 2016a).

Todos estos reparos nos hablan a las claras de que es necesaria una mirada integral de estos agentes. Ello implica también poder vislumbrar el contexto político, social, económico, cultural y jurídico que imponía límites y condicionaba la actuación de los Defensores de pobres, lo que obliga a situar su desempeño en un amplio marco de análisis.

¿Por dónde empezar entonces? En primer lugar creemos indispensable estudiar en concreto quienes eran los individuos que ocupaban dicho oficio. ¿Qué roles sociales cumplían en la comunidad? ¿Cuál era su lugar en la pirámide social? ¿En qué momento de sus vidas desempeñaban el oficio? ¿Cuáles eran sus trayectorias personales posteriores? Respondiendo a estas simples preguntas algunas de los calificativos que la historiografía había expresado al pasar cuando se refería a estos agentes de justicia pueden perder su razón de ser. Los Defensores de pobres del ayuntamiento porteño no eran funcionarios. Eran regidores rotativos que no cobraban por su tarea ni formaban parte de la burocracia real, sino que representaban a la comunidad local. Tampoco eran abogados, ya que 
ninguno de los que desempeñaron esta función en la época tardocolonial tenía formación universitaria en leyes. Y también es inexacto caracterizarlos de apasionados antiesclavistas ni mucho menos.

Al ser parte de la elite local, eran grandes propietarios de esclavos e incluso algunos se contaban entre los mayores traficantes de esclavos del virreinato como Tomás Antonio Romero o Martín de Álzaga. Incluso algunos fueron denunciados por sus propios esclavos por malos tratos, en años posteriores o anteriores a que ocupasen la función de Defensor de pobres. Es claro que la extracción social de los Defensores de pobres no determinaba automáticamente un determinado desempeño en el ejercicio de su función. Pero es un dato a tener en cuenta y permite contextualizar en términos sociales y culturales las prácticas desplegadas por estos sujetos, al mismo tiempo que obliga a cierta precaución a la hora de extraer conclusiones generales. El hecho que los hombres notables de Buenos Aires en algún momento de sus vidas hayan desempeñado el oficio tampoco es casual. Ser defensor de pobres era una “prueba de caridad” para con los pobres y un acto de “amor a la causa publica”, ya que demandaba tiempo y dinero asistir a los miserables.

Un enfoque prosopográfico tiene mucho para ofrecer a la hora de intentar responder las preguntas planteadas. El Defensor de pobres de Buenos Aires típico en la etapa tardocolonial era un vecino destacado (“español”, le antecedía el Don y era jefe de familia), de origen peninsular, casado apenas unos años antes, que se dedicaba al comercio en gran escala, de una posición económica acomodada y de un prestigio social considerable. Los defensores eran un reflejo bastante fiel local, compuesta en gran parte por grandes comerciantes importadores-exportadores. De los 36 Defensores de pobres del período 1776-1809, el 72 \% volvió a ocupar otro cargo en el Cabildo, y el 39\% llegó a ser Alcalde de $1^{\circ}$ o $2^{\circ}$ voto. Con respecto al Consulado de Comercio, de los defensores que ocuparon el cargo entre 1776 y 1809, el 55,5 \% fue miembro del Consulado, y el 25 \% llegó a ser prior o cónsul, los cuales eran los cargos más altos. Algunos Defensores, además tenían múltiples inversiones, cumplían funciones en la milicia local y participaban de las instituciones religiosas y de beneficencia.

Las biografías colectivas y los números no deben hacernos perder la singularidad de algunos casos. Por ejemplo, quién más llevó el extremo el ideal del Defensor de pobres fue Manuel Rodríguez de la Vega. Además de ser el único individuo que ejerció dos veces el cargo, en 1776 y 1779, fue un reconocido benefactor de fines de la época colonial. Fue Tesorero de la Hermandad de la Caridad y también protector del Hospital de Mujeres y de la Casa de Niños Expósitos. Ésta última había sido creada el 17 de Junio de 1779, ante el pedido de un grupo de personas destacadas, entre las que se encontraba Rodríguez de la Vega, ante el Virrey Vértiz para que se erija una institución que ampare a los niños abandonados de la ciudad.

Rodríguez de la Vega era un destacado comerciante mayorista que en 1766 había sido 
señalado por Cevallos como uno de las tres personalidades más ricas de la ciudad de Buenos Aires (TORRE REVELLO, 1970, p. 108). Trabajó como tesorero de la Casa de Niños Expósitos desde 1779 a 1795 y fue uno de los mayores benefactores de la Hermandad y de otras organizaciones religiosas de la ciudad. A diferencia de la mayoría de los Defensores de pobres era soltero, y al momento de su muerte legó toda su fortuna a la iglesia para caridad (SOCOLOW, 1991, p. 118). No en vano los regidores capitulares le hicieron un homenaje en vida y era caracterizado como un verdadero "padre de los pobres".

La Revolución de Mayo acontecida en 1810 modificó en parte el perfil social de los Defensores de pobres que ocuparon el cargo en la primera década revolucionaria en el ayuntamiento porteño. Siguieron siendo en su mayoría hombres "blancos”, sin formación en leyes, propietarios, y con cierto prestigio social. También siguieron reclutándose entre la elite de la ciudad. Pero a diferencia del período virreinal, en su gran mayoría fueron criollos, no nacidos en la península. Además en este período aparecieron unos pocos defensores con título de abogados, y otros que además de dedicarse al comercio mayorista se convirtieron en importantes hacendados con el paso del tiempo.

En segundo lugar creemos que hay que poder situar las intervenciones de los Defensores de pobres que han subsistido en los expedientes con un corpus documental más general que incluya aquellos expedientes judiciales en los cuales no intervenían. Porque si solo se analizaran las intervenciones de estos agentes de justicia, la imagen que transmiten del funcionamiento de la justicia penal puede brindar un panorama exageradamente procesalizada o “garantista”. Por ejemplo, en el fondo juzgado del crimen del Archivo Histórico de la Provincia de Buenos Aires se conservan 1281 causas criminales correspondientes al período 1776-1809, restringidas a la ciudad de Buenos Aires y su campaña. Los defensores intervinieron solo en 216, el 17 \% del total. De las Solicitudes de presos que se conservan en el Archivo General de la Nación, que son 136, los defensores redactaron solo el 3 \% (REBAGLIATI, 2015). Y de los expedientes civiles que involucraban a esclavos que demandaban a sus amos, los defensores solo tomaron parte en el 40 \%. En síntesis, los Defensores de pobres estaban lejos de monopolizar la relación que los sectores plebeyos tenían con la justicia. Y así como hay que explicar y analizar la presencia de los Defensores de pobres en estas actuaciones judiciales, también hay que preguntarse por su ausencia en la mayoría de los $\operatorname{casos}^{23}$.

\footnotetext{
${ }^{23}$ La simple constatación del hecho de que los Defensores de pobres no intervenían en la mayoría de los pleitos que los plebeyos entablaban ante la justicia abre un enorme campo de investigación. ¿De qué redes sociales se valían los sujetos de las clases populares para peticionar por sus derechos ante la justicia? ¿Con qué éxito? Estos interrogantes son la base de nuestro actual proyecto de investigación posdoctoral: “Miserables y Desamparados”. Pobres, presos y esclavos en busca de justicia (Buenos Aires, 1776-1810). El mismo cuenta con financiamiento del CONICET.
} 
La cuestión del recorte temporal que necesita delimitar toda investigación también merece unos comentarios. Es una premisa básica de toda historia social no guiarse exclusivamente por la cronología política. De la época que nos ocupa, el gran parteaguas lo representa el proceso de guerra, revolución e independencia que experimentó la región entre 1806 y 1826. Ante el temor de que resultara inabarcable estudiar en profundidad el oficio de Defensor de pobres a lo largo de su siglo de existencia (1722-1821), nos pareció mejor adoptar como punto de partida el año 1776, cuando se creó el Virreinato del Río de la Plata.

Una opción podría haber sido extender el período a analizar solo hasta 1810, enfocándonos exclusivamente en esta etapa tardocolonial. Sin embargo, de haber tomado esta decisión hubiera resultado una mirada sincrónica y estática de nuestro objeto de estudio. El extender el marco temporal hasta 1821 (año de abolición del cabildo y desaparición del oficio en cuestión) nos permitió ver las rupturas y continuidades experimentadas entre estas dos épocas. A pesar de ciertos cambios experimentados, este oficio capitular - que estaba íntimamente asociado a una cultura jurídicapolítica de antiguo régimen - pervivió con sorprendente continuidad durante toda la década revolucionaria. Prácticamente no hay iniciativas por parte de los revolucionarios para reformar radicalmente las características que reunía este agente de justicia. Si en las demás ciudades rioplatenses la aparición de la función de Defensor de pobres es aún más tardía, se vuelve más necesario adoptar marcos temporales amplios que incluyan a las primeras décadas del siglo XIX según cada caso en particular.

Las fuentes judiciales parecen ser un mirador privilegiado para recomponer una historia de carne y hueso, con sujetos que con sus acciones resisten, se adaptan, negocian, pelean y aprovechan los intersticios de la sociedad que los rodea y condiciona. En este aspecto son muy ricos los análisis cualitativos y estudios de caso que permiten describir en realidad grandes tendencias. Una tradición historiográfica como la Microhistoria Italiana ha hecho escuela en esto. Sin embargo, con todas las prevenciones del caso, la cuantificación de ciertas variables observables en los expedientes judiciales también puede brindar excelentes resultados. Se pueden trazar perfiles sociales tanto de los defensores como de sus asistidos en base al género, el lugar de nacimiento, la edad, la condición socio-étnica, el estado civil y el lugar de residencia. También se pueden cuantificar los resultados de los juicios y peticiones dirigidas al Virrey, la frecuencia de las intervenciones de los Defensores de pobres, la cantidad de las visitas de cárceles, las principales características de la población carcelaria, etc.

En este aspecto, creemos necesario combinar un análisis cualitativo y cuantitativo en igual medida a la hora de abordar a estos agentes de justicia y sus prácticas. Sobre todo a la hora de responder ciertas preguntas que consideramos nodales. ¿Era el patrocinio de los Defensores de pobres 
una imposición de los jueces a los asistidos, o una demanda genuina por parte de los justiciables? En otras palabras, ¿Actuaban los Defensores de pobres como facilitadores de los deseos, demandas y derechos insatisfechos de las clases populares que al acudir a la justicia resistían y se adaptaban al contexto social? ¿O su labor tenía como fin y consecuencia legitimar la autoridad política, sofrenar formas más violentas de protesta y fortalecer el consenso y la obediencia?

Por último, queríamos cerrar estas conclusiones con alguna reflexión sobre el enfoque macro que se revela como el más adecuado en nuestra opinión para abordar la temática. En nuestra investigación doctoral nos enrolamos en el subcampo denominado "Historia Social de la justicia"24. Nuestra preocupación por el contexto social en el cual los actores que entran en contacto con la justicia despliegan sus prácticas nos permiten creer que podemos hacer aportes importantes a una historia social concebida en términos amplios. De esta forma, nuestro objeto de estudio - un aspecto puntual de la administración de justicia - se transformó en un mirador privilegiado de la sociedad porteña tardocolonial en su conjunto. Sin embargo, abrazar un enfoque o una metodología en forma exclusiva no haría más que empobrecer nuestra mirada ${ }^{25}$. Para responder a algunos interrogantes se revela necesario establecer un diálogo con otras tradiciones historiográficas.

Toda Historia social de la justicia por cercanía temática necesariamente debe nutrirse de los aportes principales de otras dos tradiciones. La historia del derecho en su vertiente clásica o institucionalista, que ha exhumado minuciosamente buena parte de los textos legislativos y las obras de juristas, e incluso ha desempolvado expedientes judiciales para ver a la justicia en acción ${ }^{26}$. Y la historia crítica del derecho - de raigambre más reciente -, que ha develado muchas de las claves culturales que caracterizaban a la sociedad y a la cultura jurídico-política de Antiguo Régimen ${ }^{27}$. De esta forma se puede develar qué planteaban las leyes y los juristas sobre el oficio, y qué elementos de la cultura jurídica de la época eran utilizados o puestos en práctica por los Defensores de pobres en

\footnotetext{
${ }^{24}$ Básicamente, los estudios que pueden ser englobados bajo esta categoría se caracterizan por historiar algún aspecto del Derecho o la Justicia de alguna sociedad pasada en pos de explorar o analizar a los grupos sociales y sus relaciones mutuas (BARRIERA; POLIMENE, 2010, p. 9-16). Carlos Aguirre y Ricardo Salvatore hace ya más de una década se refirieron a este campo de estudios de una forma similar, usando la denominación Social History of Law (2001). Juan Manuel Palacio por ejemplo ha definido a este campo de estudios como "una historia de la relación entre justicia y sociedad que investigue las prácticas, los actores y las lógicas que articulan los sistemas judiciales, así como las formas en que han sido imaginados y percibidos por la sociedad a través del tiempo” (2005-2006, p. 99).

${ }^{25}$ Durante décadas, la historia del derecho - apegada a un paradigma legalista y dogmático -, y la historia social - que exhibió un desdén por el fenómeno jurídico - se desarrollaron por carriles separados. En tiempos recientes esta tendencia ha retrocedido y los diálogos e intercambios entre ambas disciplinas se han intensificado con fructíferos resultados (TAU ANZOÁTEGUI, 1997; BARRENECHE, 2015).

${ }^{26}$ Los máximos exponentes de esta tradición historiográfica han sido Ricardo Levene, Alfonso García Gallo, o Alamiro de Ávila Martel, entre muchos otros.

${ }^{27}$ Algunos de los autores más destacados de este campo son Antonio Hespanha, Bartolomé Clavero, Paolo Grossi, Carlos Garriga, Jesús Vallejo, Alejandro Agüero y Víctor Tau Anzoátegui.
} 
el ejercicio de sus funciones ${ }^{28}$.

Hace ya más de dos décadas, Florencia Mallon al hacer un repaso historiográfico por las distintas corrientes interpretativas de los estudios subalternos, culminaba diciendo que los historiadores debían convertirse en “jinetes acróbatas”. Con esto quería decir que los estudiosos del pasado de esta especialidad tenían que saber aprovechar la utilidad de distintos enfoques teóricos montar muchos caballos - a la hora de escribir la historia de los sectores subalternos, porque de lo contrario no podrían “cabalgar” (MALLON, 1995). Quizá lo expresado por esta historiadora sea aplicable también para quienes poco a poco pretendemos investigar y reconstruir una historia de los agentes y actores de la justicia en épocas pasadas, en pos de comprender la sociedad en la que actuaban.

\section{REFERENCIAS}

ACEVEDO, Edberto Oscar. El protector de indios en el Perú (hacia fines del régimen español). En: IX Congreso del Instituto Internacional de Historia del Derecho Indiano, Madrid, 5 a 10 de febrero de 1990: actas y estudios, v. 2. Madrid: Editorial de la Universidad Complutense, 1991, p. 29-54.

ACEVEDO, Edberto Oscar. Investigaciones sobre el Cabildo mendocino en la época independiente. En: Revista del Instituto de Historia del Derecho Ricardo Levene, n. 14, 1963, p. 11-46.

AGÜERO, Alejandro. Castigar y perdonar cuando conviene a la república. La justicia penal de Córdoba del Tucumán, siglos XVII y XVIII. Madrid: Centro de estudios políticos y constitucionales, 2008.

AGÜERO, Alejandro. Las categorías básicas de la cultura jurisdiccional. En: LORENTE SARIÑENA, Marta (Ed.). De justicia de jueces a justicia de leyes: hacia la España de 1870. Madrid: Consejo General del poder judicial - Centro de documentación judicial, 2006, p. 19-58.

AGUIRRE, Carlos; SALVATORE, Ricardo. Introduction. Writing the History of law, crime, and punishment in Latin America. En: SALVATORE, Ricardo; AGUIRRE, Carlos; Joseph, Gilbert. Crime and punishment in Latin America. Law and society since Late Colonial Times. London: Durham, 2001, p. 1-31.

ASPELL DE YANZI FERREIRA, Marcela. La visita de cárcel en Córdoba del Tucumán: Siglo XVIII. En: XI Congreso del Instituto Internacional de Historia del Derecho Indiano: Buenos Aires, 4 al 9 de septiembre de 1995: actas y estudios, v. 4. Buenos Aires: Instituto de Investigaciones

\footnotetext{
${ }^{28}$ Por supuesto, la mención a estas dos corrientes historiográficas no agotan la lista de otras tradiciones que aportan elementos significativos a una investigación de este tipo. En nuestra propia investigación nos hemos valido del resultado de estudios muy variados, provenientes de la historia social y económica en sentido amplio, la nueva historia política, la historia de la pobreza, la historia de los sectores subalternos, etc. Darío Barriera ha analizado varias de estas intersecciones entre la Historia social de la justicia y otras corrientes en un interesante artículo (2014).
} 
de Historia del Derecho, 1997, p. 277-312.

ÁVILA MARTEL, Alamiro. Aspectos del Derecho Penal Indiano. Buenos Aires: Edición del Instituto de Historia del Derecho de la Facultad de Derecho y Ciencias Sociales, 1946.

ÁVILA MARTEL, Alamiro. Esquema del Derecho Penal Indiano. Santiago: Universidad de Chile, 1941.

AZEVEDO, Elciene En las trincheras de la historia. Abogados y esclavos en el movimiento abolicionista de San Pablo. En: PALACIO, Juan Manuel; CANDIOTI, Magdalena (Comp.). Justicia, política y derechos en América Latina. Buenos Aires: Prometeo, 2007, p. 107-126.

BAEZA MARTÍN, Ascensión. Presión e intereses en torno al cargo de protector general de indios del Nuevo Reino de León: el caso de Nicolás Villalobos, 1714-1734. En: Anuario de estudios americanos, v. 67, n. 1, 2010, p. 209-237.

BARRENECHE, Osvaldo. 'A solo quitarte la vida vengo'. Homicidio y Administración de Justicia en Buenos Aires. 1784-1810. En: MAYO, Carlos (coord.). Estudios de Historia colonial rioplatense. La Plata: Universidad Nacional de La Plata, 1995, p. 7-39.

BARRENECHE, Osvaldo. Dentro de la ley, TODO. La justicia criminal de Buenos Aires en la etapa formativa del sistema penal moderno de la Argentina. La Plata: Ediciones al Margen, 2001.

BARRENECHE, Osvaldo. Esos torpes dezeos: delitos y desviaciones sexuales en Buenos Aires 1760-1810. En: Estudios de historia colonial, n. 13, 1993, p. 32-38.

BARRENECHE, Osvaldo. Las instituciones de seguridad y del castigo en Argentina y América Latina. Recorrido historiográfico, desafíos y propuestas de diálogo con la historia del derecho. En: Revista de Historia de las prisiones, n. 1, 2015, p. 5-33.

BARRIERA, Darío. La historia de la justicia y las otras historias. En: RICHARD-JORBA, Rodolfo; BONAUDO, Marta S. (Coord.). Historia Regional Enfoques y articulaciones para complejizar una historia nacional. La plata: Editorial de la Universidad Nacional de la Plata, 2014, p. 19-40.

BARRIERA, Darío; POLIMENE M. Paula. Justicias y sociedades. Bocacalles trazadas desde la historia. En: BARRIERA, Darío. La justicia y las formas de la autoridad. Organización política y justicias locales en territorios de frontera. El Río de la Plata, Córdoba, Cuyo y Tucumán, siglos XVIII y XIX. Rosario: ISHIR CONICET-Red Columnaria, 2010, p. 9-16.

BAYLE, Constantino. El Protector de Indios. Sevilla: Escuela de Estudios Hispanoamericanos, 1945.

BAYLE, Constantino. Los cabildos seculares en la América española. Madrid, Sapiencia, S. A. de Ediciones, 1952.

BERMÚDEZ AZNAR, Agustín. La abogacía de pobres en Indias. En: Anuario de historia del derecho español, n. 50, 1980, p. 1.039-1.054.

BERNAND, Carmen. Negros esclavos y libres en las ciudades hispanoamericanas. Madrid: 
Fundación Histórica Tavera, 2001.

BOIXADÓS, Roxana; FARBERMAN, Judith. Clasificaciones mestizas. Una aproximación a la diversidad étnica y social en Los Llanos riojanos del siglo XVIII. En: FARBERMAN, Judith; RATTO, Silvia (Coord.). Historias mestizas en el Tucumán colonial y las pampas (siglos XVIIXIX). Buenos Aires: Biblos, 2009, p. 79-114.

BONNETT, Diana. El protector de naturales en la Audiencia de Quito, siglos XVII y XVIII. Quito: Flacso, 1992.

BORAH, Woodrow. El juzgado general de indios en la nueva España. México: Fondo de Cultura Económica, 1985.

BORAH, Woodrow. Juzgado General de Indios del Perú o Juzgado Particular de Indios del cercado de Lima. En: Revista Chilena de Historia del Derecho, n. 6, 1970, p. 129-142.

CANDIOTI, Magdalena. Altaneros y libertinos. Transformaciones de la condición jurídica de los afroporteños en la Buenos Aires revolucionaria (1810-1820). En: Desarrollo Económico, v. 50, n. 198, 2010a, p. 271-296.

CANDIOTI, Magdalena. Ley, Justicia y Revolución en Buenos Aires, 1810-1830. Una historia política. Tesis de doctorado en Historia. Facultad de Filosofía y Letras de la Universidad de Buenos Aires, 2010b. Disponible en: <https://goo.gl/q1ACCF>.

CASAGRANDE, Agustín. Los vagabundos y la justicia de Buenos Aires durante el período tardocolonial (1785-1810). Construcciones jurídicas y criminalidad. Buenos Aires: Instituto de Investigaciones de Historia del Derecho, 2012.

CASTAÑEDA DELGADO, Paulino. La condición miserable del indio y sus privilegios. En: Anuario de Estudios Americanos, XXVIII, 1971, p. 245-335.

CEBREIROS ÁLVAREZ, Eduardo. La condición jurídica de los indios y el derecho comúnun ejemplo del "favor protectionis". En: "Panta rei”: Studi dedicati a Manlio Bellomo / Orazio Condorelli (ed. lit.), v. 1. Roma: 2004, p. 469-489.

CLAVERO, Bartolomé. Espacio colonial y vacío constitucional de los derechos indígenas. En: Anuario Mexicano de Historia del Derecho, VI, 1994, p. 61-86.

CUENA BOY, Francisco. El “defensor civitatis” y el protector de indios breve ilustración en paralelo. En: Ius fugit: Revista interdisciplinar de estudios histórico-jurídicos, n. 7, 1998b, p. 179-196.

CUENA BOY, Francisco. El protector de indios en clave romanística: una propuesta del siglo XVII. En: RASCON GARCÍA, César (Coord.). III Congreso Iberoamericano de Derecho Romano. León: Asociación Iberoamericana de Derecho Romano, 1998c, p. 87-97.

CUENA BOY, Francisco. Especialidades procesales de los indios y su sustrato romanístico. En: Anuario da Facultade de Dereito da Universidade da Coruña, 10, 2006, p. 157-167.

CUENA BOY, Francisco. Utilización pragmática del derecho romano en dos memoriales indianos 
del siglo XVII sobre el Protector de Indios. En: Revista de Estudios Histórico-Jurídicos (Sección Historia del Derecho), XX, 1998a, p. 107-142.

CUNILL, Caroline. Fray Bartolomé de las Casas y el oficio de defensor de indios en América y en la Corte española. En: Nuevo Mundo Mundos Nuevos [En línea], Debates, Puesto en línea el 18 septiembre 2012a, p. 1-18.

CUNILL, Caroline. Los Defensores de Indios de la Alcaldía mayor de Tabasco (Siglo XVI). En: HMex, LXII: 2, 2012b, p. 551-590.

CUNILL, Caroline. Los defensores de indios de Yucatán y el acceso de los mayas a la justicia colonial, 1540-1600. Mérida: Centro Peninsular en Humanidades y Ciencias Sociales-Universidad Nacional Autónoma de México, 2012c.

CUNILL, Caroline. Tomás López Medel y sus instrucciones para defensores de Indios: una propuesta innovadora. En: Anuario de Estudios Americanos, 68, 2, julio-diciembre, 2011b, p. 539-563.

CUNILL, Caroline. El indio miserable: nacimiento de la teoría legal en la América colonial del siglo XVI. En: Cuadernos Intercambio, 9, 2011a, p. 229-248.

CUTTER, Charles. The Protector de Indios in colonial New Mexico, 1659-1821. Albuquerque: University of New Mexico Press, 1986.

DE LA TORRE CURIEL, José Refugio. Un mecenazgo fronterizo: el protector de indios Juan de Gándara y los ópatas de Opodepe (Sonora) a principios del siglo XIX. En: Revista de Indias, v. 70, n. 248, ejemplar dedicado a: Vivir y morir en la frontera (México, siglos XVI-XIX), 2010, p. 185212.

DEL VALLE, Laura Cristina. Los hijos del poder. De la élite capitular a la Revolución de Mayo. Buenos Aires 1776-1810. Buenos Aires: Prometeo Libros, 2014.

DI MEGLIO, Gabriel. ¡Viva el bajo pueblo! La plebe urbana de Buenos Aires y la política entre la Revolución de mayo y el rosismo. Buenos Aires: Prometeo Libros, 2006.

DÍAZ COUSELO, José María. El Ius Commune y los privilegios de los indígenas en la América española. En: Revista de Historia del Derecho, n. 29, 2001, p. 267-306.

DÍAZ, Marisa. Las migraciones internas a la ciudad de Buenos Aires, 1744-1810. En: Boletín del Instituto de Historia Argentina y Americana “Dr. Emilio Ravignani”, tercera serie, n. 16 y 17, $2^{\circ}$ semestre de 1997 y $1^{\circ}$ semestre de 1998, p. 7-31.

DUVE, Thomas. Algunas observaciones acerca del modus operandi y la prudencia del juez en el derecho canónico indiano. En: Revista de Historia del Derecho, n. 35, 2006, p. 195-226.

DUVE, Thomas. La condición jurídica del indio y su consideración como persona miserabilis en el Derecho indiano. En: Losano, M. (Ed.). Un giudice e due leggi. Pluralismo normativo e confl itti agrari in Sud America. Milán: Università degli Studi di Milano, Dipartimento Giuridico-Politico, Collana Teoria Generale e Informatica del Diritto, 2004, p. 3-33. 
FARBERMAN, Judith; RATTO, Silvia (coord.). Historias mestizas en el Tucumán colonial y las pampas (siglos XVII-XIX). Buenos Aires: Biblos, 2009.

FERNÁNDEZ, María Alejandra. Las razones de la violencia y la fundamentación del castigo: una aproximación a las formas de acusación y de defensa en la justicia criminal (Buenos Aires, 17761810). En: GAYOL, Sandra; MADERO, Marta (Ed.). Formas de Historia Cultural. Buenos Aires: Prometeo, 2007, p. 275-304.

FRADKIN, Raúl Osvaldo. Cultura jurídica y cultura política: la población rural de Buenos Aires en una época de transición (1780-1830). En: FRADKIN, Raúl Osvaldo (Comp.). La ley es tela de araña. Ley, justicia y sociedad rural en Buenos Aires, 1780-1830. Buenos Aires: Prometeo, 2009, p. 159-186.

GARAVAGLiA, Juan Carlos. “La cuestión colonial”. Nuevo Mundo Mundos Nuevos [En linea], Debates, puesto en línea el 8 de febrero de 2005.

GARCÍA GALLO, Alfonso. La condición jurídica del indio. En: GARCÍA GALLO, Alfonso. Estudios de Historia del Derecho privado. Sevilla, 1982, p. 167-177.

GAYOL, Víctor. Los procuradores de número de la Real Audiencia de México, 1776-1824: propuesta para una historia de la administración de justicia en el Antiguo régimen a través de sus operarios. En: Chronica nova. Revista de historia moderna de la Universidad de Granada, n. 29, 2002, p. 109139.

GELMAN, Jorge. La lucha por el control del Estado: administración y elites coloniales en Hispanoamérica. En: TÁNDETER, Enrique (Dir.). Historia General de América Latina, tomo IV - “Procesos americanos hacia la redefinición colonial”. Madrid: Ediciones UNESCO/Editorial Trotta, 2000, p. 251-264.

GONZÁLEZ UNDURRAGA, Carolina. El abogado y el procurador de pobres: la representación de esclavos y esclavas a fines de la Colonia y principios de la República. En: Sudhistoria, n. 5, juliodiciembre 2012, p. 81-98.

GUZMÁN, Florencia. Los claroscuros del mestizaje. Negros, indios y castas en la Catamarca Colonial. Buenos Aires: Encuentro Grupo Editor, 2010.

HARING, Clarence. El imperio hispánico en América. Buenos Aires: Solar/Hachette, 1966.

IBAÑEZ FROCHAM, Manuel. La organización judicial argentina. Ensayo histórico. Época colonial y antecedentes patrios hasta 1853. La Plata: La Facultad, 1938.

JOFRÉ, Tomás. Causas instruidas en Buenos Aires durante los siglos XVII y XVIII. Buenos Aires: Facultad de Derecho de Buenos Aires, 1913.

JOHNSON, Lyman. A lack of legitimate Obedience and Respect: Slaves and their Masters in the Courts of Late Colonial Buenos Aires. En: Hispanic American Historical Review, 87:4, 2007, p. 631-657.

LEVAGGI, Abelardo. Historia del Derecho Penal Argentino. Buenos Aires: Editorial Perrot, 1978. 
LEVAGGI, Abelardo. La condición jurídica del esclavo en la época hispánica. En: Revista de Historia del Derecho, n. 1, Buenos Aires, 1973, p. 83-175.

LEVAGGI, Abelardo. Las cárceles argentinas de antaño (Siglos XVIII y XIX) - Teoría y realidad. Buenos Aires: Ad-Hoc, 2002.

LEVAGGI, Abelardo. Las instituciones de clemencia en el Derecho penal rioplatense. En: Revista de la Facultad de Derecho de México, XXVI, 1976, p. 246-298.

LEVAGgI, Abelardo. Manual de Historia del Derecho Argentino, tomo II. Castellano Indiano/Nacional. Judicial. Civil. Penal. Buenos Aires: Lexis Nexis, 2005.

LEVENE, Ricardo. Historia de la Nación Argentina, v. III. Buenos Aires: El Ateneo, 1961.

LEVENE, Ricardo. Historia del Derecho Argentino, tomo II. Buenos Aires: Kraft, 1945.

LEVENE, Ricardo. Introducción a la historia del Derecho Indiano. Buenos Aires: Abeledo, 1924.

LEVENE, Ricardo. Manual de Historia del Derecho del Derecho Argentino. Buenos Aires: Kraft, 1952.

LÓPEZ DÍAZ-VALENTÍN, Patricio, J. Condición jurídica del indígena americano en Hispanoamérica durante los siglos XVI y XVII. En: Fuego y Raya, 4, 2012, p. 123-149.

LUQUE COLOMBRES, Carlos. La protección de los naturales en Córdoba del Tucumán. En: Revista chilena de Historia del Derecho, n. 16, 1990, p. 229-242.

MALLO, Silvia. La libertad en el discurso del estado, de amos y esclavos. 1780-1830. En: Revista de Historia de América, n. 112, julio-diciembre 1991, p. 121-146.

MALLON, Florencia. Promesa y dilema en los estudios subalternos: perspectivas a partir de los estudios latinoamericanos. En: Boletín del Instituto de Historia Argentina y Americana Dr. E. Ravignani, n. 12, 1995, p. 87-116.

MARILUZ URQUIJO, José María. La instrucción circular para el mejor y más breve despacho de la formación de las causas criminales (1788), proyectada por el Regente Benito de la Mata Linares. En: Revista del Instituto de Historia del Derecho Ricardo Levene, n. 12, 1961, p. 173-198.

MARTIRÉ, Eduardo. La tolerancia como regla de gobierno de la Monarquía española en las Indias (siglos XVI-XVIII). En: ESCUDERO, José Antonio (Ed.). Intolerancia e Inquisición. Madrid: Sociedad Estatal de Conmemoraciones Culturales, 2005, p. 31-46.

MARTIRÉ, Eduardo. La visita de cárcel en Buenos Aires durante el Virreinato. En: Revista Chilena de Historia del Derecho, n. 13, 1987, p. 39-59.

MARTIRÉ, Eduardo. Los derechos personales en Indias. En: Revista del Instituto de Historia del Derecho Ricardo Levene, n. 26, 1980, p. 79-92.

MCFARLANE, Anthony. Los ejércitos coloniales y la crisis del imperio español, 1808-1810. En: 
Historia Mexicana, n. 229, 2008, p. 229-288.

MÉNDEZ CALZADA, Luis. La función judicial en las primeras épocas de la independencia. Buenos Aires: Losada, 1944.

NOVOA, Mauricio. The protectors of indians in the Royal Audience of Lima. History Careers and Legal Culture, 1575-1775. Leiden/Boston: Brill Nijhoff, 2016.

OLIVEROS, Martha Norma. La construcción jurídica del régimen tutelar del indio. En: Revista de Historia del Derecho Ricardo Levene, 18, 1967, p. 105-128.

OTS CAPDEQUÍ, José María. Manual de historia del derecho español en las Indias y del derecho propiamente indiano, tomo II. Buenos Aires: Universidad de Buenos Aires-Instituto de Historia del Derecho, 1943.

PALACIO, Juan Manuel. Hurgando en las bambalinas de la "paz del trigo": algunos problemas teórico-metodológicos que plantea la historia judicial. En: Quinto Sol, n. 9-10, 2005-2006, p. 99123.

PAROLO, María Paula. “Ni súplicas, ni ruegos”. Las estrategias de subsistencia de los sectores populares en Tucumán en la primera mitad del siglo XIX. Rosario: Prohistoria, 2008.

PEÑA DE MACARLUPU, Gabriela. Los derechos de los esclavos. Legislación y realidad en la Córdoba del siglo XVIII. En: Revista de Historia del Derecho, n. 23, 1993, p. 271-295.

PERRI, Gladys. Los esclavos frente a la justicia. Resistencia y adaptación en Buenos Aires, 17801830. En: FRADKIN, Raúl Osvaldo. La ley es tela de araña. Ley, justicia y sociedad rural en Buenos Aires, 1780-1830. Buenos Aires: Prometeo, 2009, p. 51-82.

PETIT MUÑOZ, Eugenio. La condición jurídica. En: PETIT MUÑOZ, Eugenio; NARANCIO, Edmundo; TRAIBEL NELCIS, José. La condición jurídica, social, económica y política de los negros durante el coloniaje en la Banda Oriental. Montevideo: Publicaciones oficiales de la Facultad de Derecho y Ciencias Sociales, 1947.

PLA, Josefina. Hermano negro. La esclavitud en el Paraguay. Madrid: Paraninfo, 1972.

PUGLIESE, María Rosa. Los defensores de pobres y menores en el período indiano. En: Congreso Internacional. 500 años de Hispanidad, 1492-1992, t. II. Mendoza: Universidad Nacional de Cuyo, Facultad de Filosofía y Letras, 1996, p. 477-499.

PUGLIESE, María Rosa. Los defensores de pobres y menores y su asesoramiento letrado en el Virreinato del Río de la Plata. En: PUGLIESE, María Rosa. De la justicia lega a la justicia letrada. Buenos Aires: Junta de estudios históricos de San José de Flores, 2000, p. 41-80.

REBAGLIATI, Lucas. 'La causa más piadosa que puede haber': Los Defensores de pobres de Buenos Aires en tiempos de revolución (1776-1821). En: ALABART, Mónica; FERNÁNDEZ, María Alejandra; PÉREZ, Mariana (Comp.). Buenos Aires una sociedad que se transforma: entre la colonia y la Revolución de Mayo. Buenos Aires: Prometeo - Universidad General Sarmiento, 2012, p. 249-286. 
REBAGLIATI, Lucas. Estrategias retóricas y cultura jurídica en el Buenos Aires virreinal: los defensores de pobres en procesos criminales (1776-1809). En: Revista de Historia del Derecho, n. 51, enero-junio 2016a, p. 127-163.

REBAGLIATI, Lucas. Los “pobres encarcelados” Prácticas y representaciones de los presos de la cárcel capitular en el Buenos Aires tardocolonial. En: Trabajos y Comunicaciones. Segunda Época, n. 41, marzo 2015, p. 1-17.

REBAGliati, Lucas. Pobreza, Caridad y Justicia en Buenos Aires: los defensores de pobres (1776-1821). Tesis de doctorado en Historia, Facultad de Filosofía y Letras de la Universidad de Buenos Aires, 2016b, inédita.

RUFER, Mario. Violencia, resistencia y regulación social de las prácticas: Una aproximación a la esclavitud desde el expediente judicial. Córdoba, fines del siglo XVIII. En: Cuadernos de Historia, Serie Economía y Sociedad, n. 4, 2001, p. 195-230.

RUIGÓMEZ GOMEZ, Carmen. Una política indigenista de los Habsburgo: el protector de indios en el Perú. Madrid: Ediciones de Cultura Hispánica, 1988.

RUIZ GUIÑAZÚ, Enrique. La magistratura indiana. Buenos Aires: Facultad de Derecho y Ciencias Sociales, 1916.

SÁENZ VALIENTE, José María. Bajo la campana del Cabildo, Organización y funcionamiento del Cabildo de Buenos Aires después de la Revolución de Mayo (1810-1821). Buenos Aires: Kraft, 1950.

SÁNCHEZ-ALBORNOZ. La población de la América colonial española. En: BETHELL, Leslie (Ed.). Historia de América Latina. Tomo 4. América Latina colonial: población, sociedad y cultura. Barcelona: Crítica, 1990, p. 15-38.

SANJURJO DE DRIOLLET, Inés Elena. Estudio sobre el Cabildo mendocino entre 1810 y 1825. Buenos Aires: Academia Nacional de la Historia, 1997.

SANJURJO DE DRIOLLET, Inés Elena. Muy ilustre cabildo, justicia y regimiento: el cabildo de Mendoza en el siglo XVIII, estudio institucional. Mendoza: Facultad de Filosofía y LetrasUniversidad Nacional de Cuyo, 1995.

SARAVIA SALAZAR, Javier Iván. La evolución de un cargo: la Protectoría de Indios en el virreinato peruano. En: Desde el Sur, volumen 4, número 1, noviembre 2011-abril 2012, p. 27-56.

SARAVIA SALAZAR, Javier Iván. Los Miserables y el Protector. Evolución de la protectoria de indios en el Virreinato peruano. Siglos XVI-XVIII. Tesis para optar al título profesional de Licenciado en Historia, Universidad Nacional de San Marcos, Facultad de Ciencias Sociales. Lima, 2012.

SOCOLOW, Susan. Los mercaderes del Buenos Aires virreinal: familia y comercio. Buenos Aires: Ediciones de la Flor, 1991.

SUÑE BLANCO, Beatriz. Evolución de la figura del protector de indios en la frontera norte de Nueva 
España. En: GUTIERREZ ESCUDERO, Antonio; LAVIANA CUETOS, María Luisa (Coord.). Estudios sobre América. Sevilla: AEA, 2005, p. 727-743.

TAU ANZOÁTEGUI, Víctor. El poder de la costumbre. Estudios sobre del derecho consuetudinario en América hispana hasta la emancipación. Buenos Aires: Instituto de Investigaciones de Historia del Derecho, 2001.

TAU ANZOÁTEGUI, Víctor. Nuevos horizontes en el estudio histórico del derecho indiano. Buenos Aires: Instituto de Investigaciones de Historia del Derecho, 1997.

TAU ANZOÁTEGUI, Víctor; AGÜERO, Alejandro (Coord.). El Derecho local en la periferia de la monarquía hispana. Buenos Aires: Instituto de Investigaciones de Historia del Derecho, 2013.

TAU ANZOÁTEGUI, Víctor; MARTIRÉ, Eduardo. Manual de Historia de las Instituciones Argentinas. Buenos Aires: Ediciones Macchi, 1981.

TELESCA, Ignacio. Mujer, honor y afrodescendientes en Paraguay a fines de la colonia. En: América sin nombre, n. 15, 2010, p. 30-38.

TÍO VALLEJO, Gabriela. Antiguo Régimen y liberalismo. Tucumán, 1779-1830. San Miguel de Tucumán: Facultad de Filosofía y Letras-Universidad Nacional de Tucumán, 2001.

TORRE REVELLO, José. La sociedad colonial, Buenos Aires entre los siglos XVI y XIX. Buenos Aires: Ediciones Pannedille, 1970.

VALLEJO, Jesús. El cáliz de plata. Articulación de órdenes jurídicos en la jurisprudencia del IUS COMMUNE. En: Revista de Historia del Derecho, n. 38, 2009, p. 1-13.

ZAMORA, Romina. '...que por su juicio y dictamen no puede perjudicar a la quietud publica...' Acerca de la administración de justicia en San Miguel de Tucumán a fines del siglo XVIII. En: POLIMENE, María Paula (coord.). Autoridades y prácticas judiciales en el Antiguo Régimen. Problemas jurisdiccionales en el Río de la Plata, Córdoba, Tucumán, Cuyo y Chile. Rosario: Prohistoria, 2011, p. 115-138.

ZAPATA DE BARRY, Ana María. El defensor de pobres como defensor de esclavos (1722 a 1839). Bahía Blanca: Editorial de la Universidad Nacional del Sur, 2013.

ZAPATA DE BARRY, Ana María. El protector de Naturales y el Defensor General de Pobres en la estructura jurídica colonial de la América Hispana. En: Ministerio Público de la Defensa, año 1, n. 3, 2007, p. 119-123.

ZORRAQUÍN BECÚ, Ricardo. El sistema político indiano. Primera parte. En: Revista del Instituto de Historia del Derecho, n. 6, 1954, p. 31-65.

ZORRAQUÍN BECÚ, Ricardo. Historia del Derecho Argentino. Buenos Aires: Editorial Perrot, 1978.

ZORRAQUÍN BECÚ, Ricardo. La organización judicial argentina en el período hispánico. Buenos Aires: Librería del Plata, 1952. 
ZORRAQUÍN BECÚ, Ricardo. Los cabildos argentinos. Buenos Aires: Imprenta de la Universidad, 1956.

Lucas Rebagliati

Doctor en Historia por la Universidad de Buenos Aires. Investigador Asistente del Consejo Nacional de Investigaciones Científicas y Técnicas (CONICET), con sede de trabajo en el Instituto de Historia de Historia Argentina y Americana “Dr. Emilio Ravignani”. Profesor de Historia Argentina I (1776-1862), en la carrera de Historia de la Facultad de Filosofía y Letras, en la Universidad de Buenos Aires. Profesor de Historia Constitucional Argentina y Latinoamericana I (1776-1912), en la carrera de Abogacía del Departamento de Ciencias Sociales, en la Universidad Nacional de Avellaneda.E-mail: lucasrebagliati@hotmail.com 